\title{
CONTROL DE CONSTITUCIONALIDAD Y CONTROL DE CONVENCIONALIDAD. COMPARACIÓN (Criterios fijados por la Corte Interamericana de Derechos Humanos)
}

\author{
Constitutional control and conventional control. comparison \\ (Criteria established by the Inter-American Court of Human Rights)
}

\author{
Juan Carlos Hitters ${ }^{1}$ \\ Profesor de Derecho Procesal, \\ Universidad de La Plata, Argentina \\ hitters@scba.gov.ar
}

RESUMEN: El 'control de convencionalidad' es un mecanismo que debe ser llevado a cabo, primero por los cuerpos judiciales domésticos, haciendo una 'comparación' entre el derecho local y el supranacional, a fin de velar por el efecto útil de los instrumentos internacionales, sea que surja de los tratados, del ius cogens o de la jurisprudencia de la Corte Interamericana de Derechos Humanos; y luego esa tarea debe ser ejercida por la Corte Interamericana de Derechos Humanos si es que el caso llega a sus estrados.

PALABRAS CLAVE: Corte Interamericana de Derechos Humanos. Control de convencionalidad. La efectividad de los instrumentos internacionales.

ABSTRACT: The conventionality 'control' is a mechanism that should be carried out first by the domestic judiciary, making a 'comparison' between local and supranational law, to ensure the effectiveness of international instruments, is arising from treaties, the jus cogens or the jurisprudence of the Inter-American Court of Human Rights, and then that task should be exercised by the Interamerican Human Rights Court if the case goes to his courtroom.

KEY WORDS: Inter-American Court of Human Rights. Conventionality control. The effectiveness of international instruments

1 El autor es Profesor de Derecho Procesal de la Universidad de La Plata y Ministro de la Corte Suprema de La Plata. Artículo recibido el 23 de junio de 2009 y aprobado el 22 de octubre de 2009. 


\section{INTRODUCCIÓN}

\section{A. Control de convencionalidad}

\section{Orígenes}

Los órganos jurisdiccionales locales -y los Tribunales Constitucionales que en determinados países no dependen del Poder Jurisdiccional- ejercitan el llamado control de constitucionalidad que importa una comparación, entre su Carta Magna y las normas que por su rango están por debajo de ella, debiendo darle prioridad a la primera. Podemos hablar entonces de un contralor concentrado, típico de algunas Constituciones Europeas, a partir de la Austriaca de 1946, donde la revisión es hecha exclusivamente por un único cuerpo diseñado para tales fines; o en su caso -como es por demás sabido-, del control difuso que debe ser llevado a cabo, como en Estados Unidos y en Argentina, por todos y cada uno de los magistrados judiciales.

Pero como lo vienen sosteniendo desde hace no mucho tiempo algunos de los Magistrados de la Corte Interamericana, dicho cuerpo ejercita lo que ha dado en llamar a partir del caso Myrna Mack Chang ${ }^{2}$ el "Control de Convencionalidad", lo que obviamente significa una comparación entre el Pacto de San José de Costa Rica y otras convenciones a las que nuestro país se ha plegado, como luego veremos, y las disposiciones del derecho interno de las naciones adheridas al modelo.

En tal sentido se expresó la Corte en el caso Trabajadores Cesados ${ }^{3}$ al sostener que “...cuando un Estado ha ratificado un tratado internacional como la Convención Americana, sus jueces también están sometidos a ella, lo que les obliga a velar porque el efecto útil de la Convención no se vea mermado o anulado por la aplicación de leyes contrarias a sus disposiciones, objeto y fin. En otras palabras, los órganos del Poder Judicial deben ejercer no sólo un control de constitucionalidad, sino también "de convencionalidad' ex officio entre las normas internas y la Convención Americana ....".

Claro está que cuando se utiliza la terminología de "control de convencionalidad”, no se quiere decir que recién a partir del citado asunto la Corte IDH haya ejercido tal potestad, porque desde siempre el cuerpo hace una comparación entre ambos esque-

2 Corte IDH, Caso Myrna Mack Chang Vs. Guatemala, Sentencia de 25 de noviembre de 2003, Serie C No. 101, Voto Concurrente Razonado del Juez Sergio García Ramírez.

3 Corte IDH, Caso Trabajadores Cesados del Congreso (Aguado Alfaro y otros) Vs. Perú, Sentencia de 24 de noviembre de 2006, Serie C No. 158, párr. 128. Ídem Corte IDH, Caso Almonacid Arellano y otros Vs. Chile, Sentencia de 26 de septiembre de 2006, Serie C No. 154, párr. 124.

4 Corte IDH, Caso Trabajadores Cesados del Congreso, cit., párr. 128; cfr. Caso Almonacid Arellano, cit., párr. 124. Véase LoIANo, Adelina, El marco conceptual del control de convencionalidad en algunos fallos de la Corte Suprema Argentina, "Arancibia Clavel", "Simón”, "Mazzeo", en Albanese, Susana, Coordinadora, El control de convencionalidad, Editorial Ediar, Buenos Aires, 2008, pp. 114 a 117. Véase también SAGüÉs, Néstor, El control de convencionalidad. En particular sobre las Constituciones Nacionales, La Ley, 2009-B, p. 761. 
mas, destacando por supuesto la prioridad de la regla supranacional; lo que en verdad ha sucedido es que desde ese momento se utiliza tal fraseología.

Dicho órgano interamericano ha dejado en claro siempre que, en principio, no se ocupa en sí de las cuestiones locales sino que su tarea es la de inspeccionar si los países han violado o no las convenciones sujetas a su competencia. ${ }^{5}$

Por ello ha establecido -sin entrometerse en las jurisdicciones locales- que una sentencia con carácter de cosa juzgada de los jueces domésticos “...tiene que ser necesariamente cumplida debido a que en ella se adopta una decisión de forma definitiva, otorgando certeza sobre el derecho o controversia discutida en el caso concreto, y tiene como uno de sus efectos la obligatoriedad. Ante este tribunal [agregó], eventualmente puede discutirse la autoridad de cosa juzgada de una decisión cuando ésta afecta derechos de individuos protegidos por la convención y se demuestra que existe una causal de cuestionamiento de la cosa juzgada". ${ }^{6}$ En ese mismo sentido ha añadido -repetimos- que sólo circunstancias excepcionales pueden conducir a que el cuerpo supranacional "...deba ocuparse de examinar los respectivos procesos internos".?

Esa doctrina que 'indirectamente' tolera la fiscalización de la actividad jurisdiccional doméstica ha sido recibida por la Corte Suprema de la Nación Argentina con cierta cautela y con algunas idas y vueltas, ${ }^{8}$ aunque en los últimos tiempos fue acatada in totum, con algunas disidencias. ${ }^{?}$

5 Como bien apuntan Albar y Cançado Trindade, no se trata en verdad de "revisar" las sentencias de los tribunales domésticos, sino de una función más importante e imprescindible dentro de un mecanismo que se jacta de ser protector de los derechos humanos, puesto que la Comisión y la Corte como únicos órganos de supervisión, pueden y deben determinar la compatibilidad o no con el Pacto de San José de cualquier acto u omisión en que incurran los Estados, a través de algunos de sus poderes, órganos o agentes (Germán, Albar y CANÇAdo Trindade, Antonio, Reflexiones sobre el futuro del sistema interamericano de derechos humanos, en El futuro del sistema interamericano de protección de los derechos humanos, Cox Editores, 1998, Costa Rica, p. 584).

6 Corte IDH, Caso Acevedo Jaramillo y otros vs. Perú, Sentencia de 7 de febrero de 2006, Serie C No.144, párr.167, entre muchos otros.

7 Corte IDH, Caso de la Masacre de Mapiripán vs. Colombia, Sentencia de 15 de septiembre de 2005, Serie C No. 13, párr. 198; Corte IDH, Caso Palamara Iribarne vs. Chile, Sentencia de 22 de noviembre de 2005, Serie C No. 135, párr. 121, etc.

8 Hitrers, Juan Carlos, Criterios establecidos por los órganos jurisdiccionales de los sistemas interamericano y europeos, La Ley, Buenos Aires, 2003-D, p. 1373.

9 Recientemente uno de los Ministros del más Alto Tribunal Nacional Argentino ha expresado que "La salvaguarda de los derechos y libertades del menor y la protección especial a que éste es acreedor, con arreglo a la Convención sobre los Derechos del Niño y a la ley 26.061, requiere que los tribunales atiendan al interés superior de aquél, llevando a cabo una supervisión adecuada, lo cual comprende el ejercicio del control de convencionalidad entre las normas jurídicas internas aplicables in concreto y los tratados internacionales enunciados en el art. 75, inciso 22, de la Constitución Nacional, siendo función elemental y notoria de los jueces hacer cesar, con la urgencia del caso, todo eventual menoscabo que sufra el menor, para lo cual dicha supervisión implica una permanente y puntual actividad de oficio" (CNS. GARCía MÉNDEZ, Emilio y Musa, María Laura s/causa N 7537. Voto del Dr. Enrique Santiago Petracchi). 
Hemos querido adelantar a modo propedéutico que ese Tribunal internacional ha sentado la postura en el sentido de que por regla, él no se ocupa de modificar en forma directa el derecho interno, ya que su misión consiste en 'controlar' si las normas locales acatan -o no- las convenciones internacionales; y por ende no se convierte en una 'cuarta instancia' que deja sin efecto las leyes de los países. ${ }^{10}$

Surge de lo antedicho que la misión prístina de la Corte IDH está en llevar a cabo una inspección de convencionalidad 'comparando' la norma del derecho interno ${ }^{11}$ en relación a la convención y desentrañar si aquélla violenta a ésta. Conjugando las ideas hasta ahora expuestas podemos decir -con algunas aclaraciones que luego haremosque del postulado liminar antedicho surge que la Corte regional no se ocupa -por principio- de la legislación doméstica, sólo escruta si la misma transgrede la Convención Americana sobre Derechos Humanos (y otros tratados), y si advierte esa falencia, así se lo hace saber al país infractor para que modifique los actos ejecutados por cualquiera de sus tres poderes. Ello a fin de evitar que el mismo incurra en responsabilidad estatal (arts. 1.1 y 2 del Pacto aludido). ${ }^{12}$

Conviene alertar sobre la importancia de tal tarea que lleva a cabo la Corte a través de este contralor heterónomo, ${ }^{13}$ que importa de alguna manera una especie de "casación regional' que sirve para unificar la interpretación jurídica de los países plegados al modelo, que abarca en el ámbito interamericano más de trescientos millones de habitantes. ${ }^{14}$

Lo cierto es que este 'control de convencionalidad' no sólo se ejercita en el sistema regional correspondiente al área de los derechos humanos, sino también que dicha

10 HITters, Juan Carlos, ¿Son vinculantes los pronunciamientos de la Comisión y de la Corte Interamericana de Derechos Humanos?, La Ley 2008-E, p. 1169.

11 Para esclarecer si el Estado ha violado o no sus obligaciones internacionales, por las actuaciones de órganos judiciales, puede conducir a que la Corte deba ocuparse de examinar los procesos internos. (Corte IDH, Caso Palamara Iribarne Vs. Chile, Sentencia de 22 de noviembre de 2005, Serie C No. 135, párr. 121). En el Caso Acevedo Jaramillo (Corte IDH, Caso Acevedo Jaramillo y otros Vs. Perú, Sentencia de 7 de febrero de 2006, Serie C No. 144, par. 167) la Corte señaló que “...eventualmente puede discutirse la autoridad de cosa juzgada de una decisión cuando ésta afecta derechos de individuos protegidos por la Convención y se demuestra que existe una causal de cuestionamiento de la cosa juzgada, lo cual no ha ocurrido en el presente caso ..." (Cfr. Caso Gutiérrez Soler. Sentencia de 12 de septiembre de 2005. Serie C No. 132, párr. 98; Caso Carpio Nicolle y otros. Sentencia de 22 de noviembre de 2004. Ser ie C No. 117, párr. 131; y Caso Genie Lacayo. Solicitud de Revisión de la Sentencia de 29 de enero de 1997. Resolución de la Corte de 13 de septiembre de 1997. Serie C No. 45, párrs. 10 a 12).

12 Hirters, Juan Carlos, Responsabilidad del Estado por violación de Tratados Internacionales, La Ley 2007 C, p. 875 .

13 Cuando decimos heterónomo, no estamos hablando de una inspección hecha por cuerpos extranjeros, ya que tanto la Comisión IDH como la Corte IDH forman parte del Sistema Interamericano, por lo que obviamente no pueden entenderse como extraños a nuestro sistema regional.

14 El último protocolo de la versión Consolidada del Tratado de la Unión Europea regula en su artículo 56 un 'recurso de casación' ante el Tribunal de Luxemburgo, contra las sentencias dictadas por el órgano jurisdiccional de Primera Instancia de dicha Comunidad. 
inspección se cumple desde antiguo en el derecho comunitario, ${ }^{15}$ sea por los jueces nacionales como por el propio Tribunal de Luxemburgo. ${ }^{16}$

En efecto, desde la famosa sentencia "Costa vs. ENEL" dictada por este cuerpo judicial internacional, en el año $1964,{ }^{17}$ el mismo sostuvo que las leyes comunitarias, tanto primarias como secundarias, han sido consistentemente proclamadas por ese organismo como preeminentes tanto frente a las leyes internas anteriores, como a las posteriores (incluyendo las leyes constitucionales nacionales). ${ }^{18}$

Estos criterios han quedado firmes en la versión consolidada del Tratado de la Unión Europea y en sus Protocolos.

\section{Desarrollo de la institución. Progresividad}

Como vimos, la terminología utilizada, esto es "control de convencionalidad", fue manejada por primera vez, en el mencionado caso Myrna Mack Chang, en el año 2003, a través del voto razonado del Juez Sergio García Ramírez. ${ }^{19}$

El 7 de diciembre de 2004 en el caso Tibi, ${ }^{20}$ dicho magistrado volvió a poner la Pica en Flandes sobre esta problemática, sosteniendo, con buen tino, que la tarea de los jueces trasnacionales se asemeja a la de los Tribunales Constitucionales, ya que estos últimos inspeccionan los actos impugnados -disposiciones de alcance general- a la luz de las reglas, los principios y valores de las leyes fundamentales, "La Corte Interamericana, por su parte, analiza los actos que llegan a su conocimiento en relación con normas, principios y valores de los tratados en los que funda su competencia contenciosa. Dicho de otra manera, si los tribunales constitucionales controlan la 'constitucionalidad', el tribunal internacional de derechos humanos resuelve acerca de la 'convencionalidad' de esos actos. A través del control de constitucionalidad, los órganos

15 Hitters, Juan Carlos, Legitimación democrática del Poder Judicial y Control de Constitucionalidad, en Justicia: Revista de Derecho Procesal, ISSN 0211-7754, №2, 1987, pp. 421-434. Ídem mismo autor, Solución de controversias en el ámbito del Mercosur - Hacia un derecho comunitario, La Ley, 1997-C, p. 1406, véase punto "C" y nota 17. Conf. mismo autor, Derecho Internacional de los Derechos Humanos, Editorial Ediar, Buenos Aires, 1991, Tomo 1, pp. 29 y ss.; ídem Hitrers, Juan Carlos y Fappiano, Oscar, Derecho Internacional de los Derechos Humanos, $2^{\circ}$ edición, Editorial Ediar, Buenos Aires, 2007, Tomo 1, Volumen 1, pp. 79 y ss.

16 Cappelletti, Mauro, El "formidable problema" del control judicial y la contribución del análisis comparado, en Revista de Estudios Políticos, ISSN 0048-7694, № 13, 1980, Traducción de Faustino González, pp. 61-104.

17 Tribunal de Justicia de las Comunidades Europeas, Caso 6/64, “Costa vs. ENEL”, en E.C.R., 1964, p. 585.

18 El principio de autonomía quedó perfectamente dibujado hace ya tiempo en el caso "Van Gen en Loos”, donde ese tribunal expresó que el Derecho comunitario es un nuevo orden jurídico, en cuyo beneficio los Estados signatarios han limitado ciertas esferas de su soberanía. A su vez en el leadin case "Costa vs. ENEL", dejó sentada la doctrina de la supremacía de las disposiciones normativas de la Comunidad.

19 Corte IDH, Caso Myrna Mack Chang, cit.

20 Corte IDH, Caso Tibi Vs. Ecuador, Sentencia de 7 de septiembre de 2004, Serie C No. 114. 
internos procuran conformar la actividad del poder público $-\mathrm{y}$, eventualmente, de otros agentes sociales- al orden que entraña el Estado de Derecho en una sociedad democrática. El tribunal interamericano, por su parte, pretende conformar esa actividad al orden internacional acogido en la convención fundadora de la jurisdicción interamericana y aceptado por los Estados partes en ejercicio de su soberanía". ${ }^{21}$

Aclara allí el citado jurista mexicano que del mismo modo que un Tribunal Constitucional no puede, ni lo debe pretender, traer ante sí todos los casos en que se cuestione la supralegalidad de actos y normas; "un tribunal internacional de derechos humanos no aspira -mucho menos todavía que el órgano nacional-a resolver un gran número de litigios en los que se reproduzcan violaciones previamente sometidas a su jurisdicción y acerca de cuyos temas esenciales ya ha dictado sentencias que expresan su criterio como intérprete natural de las normas que está llamado a aplicar, esto es, las disposiciones del tratado internacional que invocan los litigantes. Este designio, que pone de manifiesto una función de la Corte, sugiere también las características que pueden tener los asuntos llevados a su conocimiento". ${ }^{22}$

Lo expresado significa -en definitiva- que en el ámbito regional, el país debe tener en cuenta "la jurisprudencia" de ese órgano supranacional y poner en marcha tales criterios en el campo doméstico.

En el caso Raxcacó Reyes ${ }^{23}$ la Corte IDH, llevando a cabo el "control de convencionalidad", ${ }^{24}$ entre el Pacto de San José y el Código Penal guatemalteco, consideró que este último infringía los postulados de aquél, por lo que dispuso que el país debería modificar esta norma punitiva, que permite la pena de muerte en determinadas circunstancias, y que mientras que no se cumpla con tal mandato jurisdiccional "El Estado deberá abstenerse de dictar la pena de muerte y ejecutar a los condenados por el delito de plagio y secuestro...". ${ }^{25}$

En el año 2006 en el asunto López Álvarez ${ }^{26}$ el juez García Ramírez, volvió sobre esta temática cuando le tocó analizar el 'plazo razonable' (arts. 7.5 y 8.1 del Pacto), sosteniendo que “...el 'control de convencionalidad' debe explorar las circunstancias de jure y de facto del caso. Es posible que el análisis jurídico sea relativamente senciIlo, una vez establecidos los hechos acerca de los cuales se ha producido el litigio, pero éstos pueden ser extraordinariamente complejos y hallarse sujetos a pruebas

21 Corte IDH, Caso Tibi, cit., voto concurrente razonado del Juez Sergio García Ramírez, párr. 3.

22 Corte IDH, Caso Tibi, cit., voto concurrente razonado del Juez Sergio García Ramírez, párr. 4.

23 Corte IDH, Caso Raxcacó Reyes Vs. Guatemala, Sentencia de 15 de septiembre de 2005, Serie C No. 133.

24 En este caso no se utilizó expresamente la frase 'control de convencionalidad'.

25 Corte IDH, Caso Raxcacó Reyes, cit., párr. 145, subpuntos 5, 6, 7 y 8. Se le había impuesto al señor Roland Raxcacó Reyes la pena de muerte por la comisión del delito de plagio y secuestro, pese a que dicha sanción no se encontraba prevista en la ley al momento que Guatemala ratificó la Convención Americana, sólo se admitía cuando como consecuencia de tales hechos, falleciera la persona secuestrada, que no era el caso juzgado.

26 Corte IDH, Caso López Álvarez Vs. Honduras, Sentencia de 1 de febrero de 2006, Serie C No. 141. 
difíciles, necesariamente prolongadas o de complicada, costosa, azarosa o tardía recaudación. También puede suceder lo contrario: relativa claridad y sencillez de los hechos, en contraste con problemas severos en la apreciación jurídica o en la calificación de aquéllos: pareceres encontrados, jurisprudencia cambiante, legislación incierta, razones atendibles en sentidos diferentes o discrepantes". ${ }^{27}$

En el caso Almonacid Arellano ${ }^{28}$-ahora- la Corte 'en pleno' se ocupó de tal problemática -refiriéndose a delitos de lesa humanidad-, sosteniendo que es consciente que los jueces y tribunales internos están sujetos al imperio de la ley, y obligados por ende a aplicar las normas vigentes en el ordenamiento jurídico. Pero cuando el Estado ha ratificado un Tratado, como el Pacto de San José, 'sus jueces' "como parte del aparato Estatal, también están sometidos a ella", ${ }^{29}$ lo que les obliga a velar para que los efectos de la Convención no se vean mermados por la aplicación de normas jurídicas contrarias a su objeto y fin. En otras palabras "el Poder Judicial debe ejercer una especie ${ }^{30}$ de "control de convencionalidad' entre las normas jurídicas internas, que aplican a los casos concretos y la Convención Americana sobre Derechos Humanos. En esta tarea el Poder Judicial debe tener en cuenta no solamente el Tratado sino también la interpretación que del mismo ha hecho la Corte IDH, intérprete última de la Convención"31 (énfasis añadido).

Repárese que en el asunto referido el Tribunal Interamericano -en pleno- utilizó por primera vez la frase 'control de convencionalidad'.

En el caso Vargas Areco $^{32}$ fallado en septiembre de 2006, nuevamente el Juez Sergio García Ramírez en su Voto Razonado trabajó sobre esta álgida cuestión hablando de 'control de convencionalidad'. ${ }^{33}$

Tales expresiones del Magistrado aludido apuntan a noticiar que la Corte IDH debe confrontar las circunstancias internas, tales como actos administrativos, leyes, resoluciones judiciales, etc.; con las normas de la Convención y resolver si existe congruencia -examen de compatibilidad-entre aquéllos y éstas. ${ }^{34}$

Desde esa vertiente, no debemos olvidar que la lógica del modelo tutelar del Pacto de Costa Rica, reside en la necesidad de apreciar la racionalidad, oportunidad, necesidad, pertinencia y proporcionalidad de determinados hechos desde la perspectiva de los derechos humanos "... esto es evidente y de ello se ha ocupado la jurisprudencia de la Corte Interamericana, cuando se trata de considerar los límites y restricciones

27 Corte IDH, Caso López Álvarez, cit., voto concurrente razonado del Juez Sergio García Ramírez, párr. 30

28 Corte IDH, Caso Almonacid Arellano, cit.

29 Corte IDH, Caso Almonacid Arellano, cit., párr. 124.

30 SAGüés, Néstor, El control de convencionalidad, ob. cit.

31 Corte IDH, Caso Almonacid Arellano, cit., párr. 124.

32 Corte IDH, Caso Vargas Areco Vs. Paraguay, Sentencia de 26 de septiembre de 2006, Serie C No. 155.

33 Corte IDH, Caso Vargas Areco, cit., voto concurrente razonado del Juez Sergio García Ramírez, párr. 6.

34 Corte IDH, Caso Vargas Areco, cit., voto concurrente razonado del Juez Sergio García Ramírez, párr. 7. 
para el ejercicio de los derechos o la suspensión de las obligaciones del Estado en esta materia. Cabe decir otro tanto del régimen de garantía establecido por la Convención -e inherente a las obligaciones naturales de un Estado en este ámbito-, al que también se pueden y deben aplicar aquellos patrones de apreciación para estimar su existencia y eficacia, y en este sentido, su correspondencia con la propia Convención". ${ }^{35}$

El 24 de noviembre de 2006, el Tribunal de marras en el caso de los Trabajadores Cesados, ${ }^{36}$ todos los jueces abordaron esta cuestión de control de convencionalidad. ${ }^{37}$ Posteriormente el Juez Cançado Trindade añadió conceptos en el mismo asunto aunque ahora en el año 2007, cuando se ocupó de la solicitud de interpretación de la sentencia. ${ }^{38}$

Conviene reiterar que en el citado caso del año 2006 la Corte no habló ya de "una especie' de control, sino que directamente lo calificó como 'control de convencionalidad', lo que hace presumir que dicha terminología quedó a partir de ese momento anclada en los andariveles de ese cuerpo.

En el segundo de los expedientes citados (Solicitud de Interpretación), ${ }^{39}$ el Juez Cançado Trinidade ${ }^{40}$ en su Voto Disidente, hizo un excelente análisis de la institución que venimos abordando, hablando - con cita de Cappelletti ${ }^{41}$ - de la dimensión constitucional y de la dimensión supranacional del derecho (tema del que nos hemos ocupado en varios trabajos anteriores). ${ }^{42}$ Puso énfasis en sostener $-y$ esto parécenos de mucha importancia- que la necesidad de agotamiento de los recursos efectivos del derecho interno ${ }^{43}$ (artículo 46.1 a de la CADH) integra la propia protección internacional de los derechos humanos (aquí vuelve a su voto del 2006 en el Caso de Trabajadores Cesados). ${ }^{44}$

35 Corte IDH, Caso Vargas Areco, cit., voto concurrente razonado del Juez Sergio García Ramírez, párr. 8.

36 Corte IDH, Caso Trabajadores Cesados del Congreso, cit.

37 Corte IDH, Caso Trabajadores Cesados del Congreso, cit., párr. 128.

38 Corte IDH, Caso Trabajadores Cesados del Congreso (Aguado Alfaro y otros). Vs. Perú, Solicitud de Interpretación de la Sentencia, Sentencia de 30 de noviembre de 2007, Serie C No. 174, Voto Disidente del mencionado Juez.

39 Corte IDH, Caso Trabajadores Cesados del Congreso, Solicitud de Interpretación de la Sentencia, cit.

40 Corte IDH, Caso Trabajadores Cesados del Congreso, Solicitud de Interpretación de la Sentencia, cit., voto concurrente razonado del Juez Cançado Trindade.

41 Cappellettr, Mauro, La Justicia Constitucional (Estudios de Derecho Comparado), México, UNAM, 1987, p. 239. Î́dem mismo autor, El "formidable problema" del control judicial y la contribución del análisis comparado, ob. cit.

42 Véase, Hrtrers, Juan Carlos, Derecho Internacional de los Derechos Humanos, 1991, ob. cit., Tomo 1, p. 29, párr. 9, punto III, nota 33; ídem Hitters, Juan Carlos y Fappiano, Óscar, Derecho Internacional de los Derechos Humanos, $2^{\circ}$ edición, 2007, ob. cit., Tomo 1, Volumen 1, p. 79, párr. 9, punto III, nota 102 [HITters, Juan Carlos, El Derecho Procesal Constitucional, en Revista El Derecho, T. 121, p. 881; ídem en Estudios de Derecho Constitucional Panameño, Compilador Jorge Fabrega, Panamá, 1987, p. 865]. Ídem Cappelletti, Mauro, Acceso a la Justicia, Revista del Colegio de Abogados de La Plata, Año XXIII, N 41. Ídem Giustizia Costituzionale Soprannazionale, en Rivista Di Diritto Processual, anno XXXIII, T. II, 1978.

43 HrTters, Juan Carlos, Derecho Internacional de los Derechos Humanos, 1991, ob. cit., Tomo II, pp. 348 y ss.

44 Corte IDH, Caso Trabajadores Cesados del Congreso, Solicitud de Interpretación de la Sentencia, cit., voto concurrente razonado del Juez Cançado Trindade, párr. 11. 
Sostiene allí el Juez de marras que el art. 2 del Pacto al imponer esa obligación de ‘armonización' entre el derecho nacional y el internacional se abre el camino para una ‘constitucionalización' de una convención supranacional. ${ }^{45}$

El 20 de septiembre de 2007, en el caso Boyce, ${ }^{46}$ la Corte se ocupó nuevamente de esta temática, ${ }^{47}$ observando que en la jurisdicción interna se había hecho un análisis puramente constitucional de la cuestión litigiosa en la cual no se tuvieron en cuenta las obligaciones que tiene el Estado conforme al Pacto de San José. Se dijo allí que de acuerdo con la Convención de Viena sobre los Tratados (art. 26), el Estado debió cumplir de buena fe con sus obligaciones convencionales, “...y no podrá invocar disposiciones de su derecho interno como justificación para el incumplimiento de dichas obligaciones convencionales...". ${ }^{48}$

Ejemplificando, y con un tono docente se señaló allí que la jurisdicción interna no se debió limitar a evaluar si la norma local era constitucional o no, ya que la Corte de Justicia del Caribe (último órgano doméstico), debió también decidir si la ley de Barbados, esgrimida en las sentencias locales, violó o no la Convención ${ }^{49}$ (énfasis añadido).

En el Caso Heliodoro Portugal, ${ }^{50}$ en un asunto referido a la desaparición forzada de personas, el Tribunal de cita adunó que a través de lo que se denomina 'control de

45 En el caso Penal Castro Castro (Corte IDH, Caso del Penal Miguel Castro Castro Vs. Perú, Sentencia de 25 de noviembre de 2006, Serie C No. 160), en su voto razonado, el Juez García Ramírez volvió a hacer referencia al tema que nos ocupa, sosteniendo que a través del 'control de convencionalidad' la Corte IDH explora “...en el universo normativo al que debe disciplinar su desempeño las disposiciones que le confieren o le niegan atribuciones para conocer de ciertas contiendas. Esta es la primera cuestión que analiza y resuelve el órgano jurisdiccional que recibe una demanda de justicia. El punto no reviste mayor complicación cuando existe una norma clara, enfática, que de manera directa y explícita confiere esas atribuciones. Obviamente, tampoco la hay cuando la norma niega semejante posibilidad o la concede a un órgano diferente de aquel que está analizando y resolviendo sobre su propia competencia..." (Corte IDH, Caso del Penal Miguel Castro Castro, cit., voto concurrente razonado del Juez Sergio García Ramírez, párr. 16), agregando que “...Existe una tercera situación, que se plantea cuando las disposiciones del ordenamiento sobre derechos humanos contienen algún régimen sobre el control de la materia por parte de los órganos internacionales de protección, pero la fórmula que utilizan no es por sí misma, prima facie, suficientemente explícita o unívoca, o difiere de la utilizada en otros casos. En esta hipótesis, el tribunal debe interpretar la disposición y hallar su significado. No digo, por supuesto, que debe 'integrar' el ordenamiento y crear, a partir de su voluntad o de su imaginación, una competencia que no se encuentra recogida, en lo absoluto, en la norma sobre control de convencionalidad de los actos del Estado. Su poder no llega tan lejos: sólo debe desentrañar el sentido de la disposición oscura o elusiva y establecer, a través de ese proceso lógico-jurídico, su sentido y alcance. Es esto lo que ha hecho la Corte Interamericana a propósito de la Convención de Belém do Pará, y su aplicabilidad al presente caso..." (Corte IDH, Caso del Penal Miguel Castro Castro, cit., voto concurrente razonado del Juez Sergio García Ramírez, párr. 17).

46 Corte IDH, Caso Boyce y otros Vs. Barbados, Sentencia de 20 de noviembre de 2007, Serie C No. 169.

47 Se trataba de una sentencia que dispuso la pena de muerte de dos personas y una norma del derecho interno de Barbados no permitia a los Tribunales que declaren la inconstitucionalidad dicha máxima sentencia.

48 Corte IDH, Caso Boyce, cit., párr. 77. Véase SAGüÉs, Nestor, ob. cit.

49 Corte IDH, Caso Boyce, cit., párr. 78.

50 Corte IDH. Caso Heliodoro Portugal Vs. Panamá. Excepciones Preliminares, Fondo, Reparaciones y Costas. Sentencia de 12 de agosto de 2008. Serie C No. 186, párrs. 180-181. 
convencionalidad', cada juzgador debe velar por el efecto útil de los instrumentos internacionales, por ende, el derecho doméstico - tal cual ya lo dijimos- debe adecuar sus normas al Pacto de San José.

La Corte ha interpretado que la 'adecuación' de los preceptos locales “... implica la adopción de medidas en dos vertientes, a saber: i) la supresión de las normas y prácticas de cualquier naturaleza que entrañen violación a las garantías previstas en la Convención o que desconozcan los derechos allí reconocidos u obstaculicen su ejercicio; y ii) la expedición de normas y el desarrollo de prácticas conducentes a la efectiva observancia de dichas garantías", ${ }^{51}$ criterio que ya había sido fijado con anterioridad.

\section{Control de convencionalidad en abstracto}

Conviene poner de resalto que en los primeros tiempos tal Tribunal Interamericano sostenía que era improcedente la revisión supranacional si el precepto atacado no había sido aplicado. Empero últimamente el órgano aludido cambió de tornas destacando su potestad de controlar la convencionalidad de las normas locales, aún en abstracto. ${ }^{52}$

En efecto, el 27 de enero de 1995 en el caso Genie Lacayo ${ }^{53}$ había expresado que “...La competencia contenciosa de la Corte no tiene por objeto la revisión de las legislaciones nacionales en abstracto sino que es ejercida para resolver casos concretos en que se alegue que un acto del Estado, ejecutado contra personas determinadas, es contrario a la Convención..."; concluyendo que no tiene aptitud para activar ex officio 'en abstracto' el contralor de convencionalidad, criterio que mantuvo a rajatabla en el mismo asunto el 29 de enero de 1997 en la sentencia sobre el fondo. ${ }^{54}$

Tal pauta fue criticada en estas últimas actuaciones por el entonces Juez Cançado Trindade en su Voto Disidente, quien abriendo una brecha en la sólida jurisprudencia precedente, dejó en claro que la infracción convencional se produce por el solo hecho de que la norma doméstica esté vigente (aunque no haya sido aplicada); añadiendo luego en el caso "El Amparo" que para que exista maltrato a la CADH "...no me parece necesario esperar la ocurrencia de un daño....".55

51 Corte IDH. Caso Heliodoro Portugal, cit., párr. 180.

52 Sobre el particular puede verse el importante libro del profesor colombiano Ernesto Rey Cantor, a donde nos remitimos brevitatis causa, dado que lleva ahí análisis pormenorizado de la temática (Control de Convencionalidad de las Leyes y Derechos Humanos, Editorial Porrúa, México, 2008, pp. 68, 69, 70, 71 y ss.).

53 Corte IDH, Caso Genie Lacayo Vs. Nicaragua, Excepciones Preliminares, Serie C No. 21, párr. 50.

54 Corte IDH, Caso Genie Lacayo Vs. Nicaragua, Fondo, Serie C No. 30, párr. 91.

55 Corte IDH, Caso El Amparo Vs. Venezuela, Sentencia de 14 de septiembre de 1996, Serie C No. 28, Voto Disidente del Juez Cançado Trindade, párr. 3. Agregó dicho magistrado que “...un individuo puede, bajo determinadas condiciones, reivindicar ser víctima de una violación de derechos humanos perpetrada por la simple existencia de medidas permitidas por la legislación, sin que hayan sido a él aplicadas..." (párr. 5). 
En una segunda etapa -como puntualiza Rey Cantor ${ }^{56}$ - se muestra un cierto cambio en la jurisprudencia aludida, al sostener la Corte IDH en el caso Suárez Rosero ${ }^{57}$ y posteriormente en Castillo Petruzzi ${ }^{58}$ entre otros, que puede haber infracción al Pacto de San José aún cuando el dispositivo normativo doméstico no haya sido aplicado en un asunto concreto.

En una apretada síntesis podemos decir que en las últimas épocas ese Tribunal efectuó como siempre el control de convencionalidad de los preceptos del derecho doméstico aplicados al caso concreto; y también de aquellas reglas que habiendo sido sancionadas $-y$ vigentes- no hubieran sido utilizadas en una causa determinada. ${ }^{59}$

\section{PARTICULARIDADES}

\section{A. ¿Quiénes ejercen este control?}

Quedó remarcada, en el caso Almonacid Arellano ${ }^{60}$-entre otros-, la pauta a la que antes hemos hecho referencia, en el sentido de que no sólo el Tribunal Interamericano debe llevar a cabo el contralor de marras, sino también que previamente los jueces locales pueden y deben ejercitar esta tarea, obviamente antes que el pleito llegue a la instancia internacional. Ello así porque -reiteramos- la intervención de los cuerpos supranacionales es subsidiaria y las actuaciones -por regla- deben ser analizadas en la instancia doméstica sin perjuicio del eventual "salto" a los andariveles interamericanos. De ahí que el Pacto impone la necesidad de "agotar los derechos internos” (art. 46.1.a).

Como expresamos, se trata de aplicar primero el 'control de constitucionalidad' a través del juez local, quien debe también llevar a cabo la inspección de 'convencionalidad', sucede algo similar a lo que acaece en el orden interno con la cuestión federal, ya que según la clásica jurisprudencia de Corte Suprema de Justicia de la Nación, la norma debe ser analizada primero por los cuerpos judiciales provinciales y luego, si subsiste el agravio, por el más alto cuerpo de justicia del país.

56 Rey CANTor, Ernesto. Control de Convencionalidad de las Leyes y Derechos Humanos, ob. cit., pp. 81 a 93.

57 Corte IDH, Caso Suárez Rosero Vs. Ecuador, Sentencia de 12 de noviembre de 1997, Serie C No. 35 , párr. 98; apuntalando ese criterio véase también el Voto Razonado del Juez Cançado Trindade en el caso "La Última Tentación de Cristo" (Corte IDH, Caso "La Última Tentación de Cristo" [Olmedo Bustos y otros] Vs. Chile, Sentencia de 5 de febrero de 2001, Serie C No. 73, párr. 13.

58 Corte IDH, Caso Castillo Petruzzi y otros Vs. Perú, Sentencia de 30 de mayo de 1999, Serie C No. 52.

59 En definitiva esta inspección de compatibilidad puede ejercitarse preventivamente, como en el caso de algunos Tribunales Constitucionales Europeos (de jurisdicción concentrada). En la Provincia de Buenos Aires el Código Procesal Civil y Comercial regula esta posibilidad en los arts. 686 a 688 (conforme art. 161.1 de la Constitución Provincial bonaerense) que tramita directamente ante la Suprema Corte de dicho Estado.

60 Corte IDH, Caso Almonacid Arellano, cit. 


\section{B. ¿Sobre qué normas supranacionales se debe ejercitar el control de convencionalidad?}

Tal cual ya lo hemos expresado repetidamente, tanto los judicantes domésticos como los de la Corte IDH, deben buscar la 'compatibilidad' entre las normas locales y las supranacionales. En este aspecto cabe repetir, que cuando hablamos de estas últimas no nos referimos sólo al Pacto de San José, sino a otros Tratados Internacionales ratificados por la Argentina, al ius cogens y a la jurisprudencia de la Corte IDH.

Al aludir a las normas internacionales se pueden citar: el Protocolo de San Salvador; el Protocolo Relativo a la Abolición de la Pena de Muerte; la Convención para Prevenir y Sancionar la Tortura; la Convención de Belém do Pará para la Erradicación de la Violencia contra la Mujer, la Convención sobre Desaparición Forzada, etcétera; que integran el copus iuris convencional de los derechos humanos, ${ }^{61}$ tal cual quedó dicho.

\section{C. ¿Sobre qué normas nacionales se debe ejercer la ‘comparación'?}

Tal cual hemos visto, una consecuencia de la violación de las disposiciones supranacionales es la necesidad de 'adecuar' o, lo que es lo mismo, 'amoldar' o 'adaptar', las reglas del derecho interno a los Tratados. Esto implica que si los preceptos domésticos -sean legislativos o de cualquier otro carácter-, y las prácticas estaduales de cualquiera de los tres poderes, no protegen debidamente las libertades fundamentales enunciadas por el derecho internacional, la nación debe adecuarlas, y, en su caso, suprimir aquellas que desbordan el esquema, o crear las que corresponda. Estamos hablando del deber general del Estado de 'adecuación' de las reglas domésticas (arts. 1.2 y 2 de la Convención). ${ }^{62}$

Vale la pena reiterar, entonces, que el control de convencionalidad tiene que hacerse a través de una 'comparación' -que deben cumplir los judicantes del país- entre las reglas internas de esencia legislativa, administrativa o de cualquier otro carácter, ${ }^{63}$ por un lado; y los Tratados aludidos, la jurisprudencia de la Corte IDH y el ius cogens, por el otro.

En puridad de verdad, la Corte no ha hecho una descripción de qué tipo de preceptos locales deben ser controlados, por lo que consideramos que cualquier regla de alcance general y abstracto mal aplicada (ley, decreto, ordenanza, actos administrati-

61 Corte IDH, Caso Trabajadores Cesados del Congreso, noviembre de 2006, cit., Voto Concurrente razonado del Juez Sergio García Ramírez, párr. 2

62 Caso "Instituto de Reeducación del Menor", Sentencia de 2 de septiembre de 2004, Serie C N 112 , nota 135, HrtTers, Juan Carlos, Responsabilidad del Estado por violación de Tratados Internacionales, La Ley 2007-C, p. 875, nota 23.

63 Hitrers, Juan Carlos, Técnica de los Recursos Extraordinarios, Librería Editora Platense, Buenos Aires, $2^{\text {a }}$ edición, p. 259. 
vos, constituciones provinciales y nacional), tiene que estar incluida en el concepto aludido. ${ }^{64}$

Como bien se ha expresado, en los países donde la doctrina jurisprudencial fijada por el Tribunal Constitucional o por la Corte Suprema es obligatoria para los tribunales inferiores, ella reviste el carácter de 'norma' o 'ley' y por ende puede y debe ser incluida en el contralor al que nos venimos refiriendo. ${ }^{65}$

\section{Control de oficio.}

En nuestro país y en algunos otros - depende de la normativa vigente- se discute si el control de constitucionalidad debe ser llevado a cabo a pedido de parte o de oficio. ${ }^{66}$

Sin perjuicio de lo que en definitiva resuelven los tribunales locales, reiteramos que según la interpretación de la Corte IDH “....los órganos del Poder Judicial deben ejercer no sólo un control de constitucionalidad, sino también 'de convencionalidad' ${ }^{\prime \prime}$ ex officio entre las normas locales y la Convención Americana, evidentemente en el marco de sus respectivas competencias y de las regulaciones procesales correspondientes. ${ }^{68}$ Esta

64 En el Caso Yatama Vs. Nicaragua, Sentencia de 23 de junio de 2005, Serie C No. 127, párr. 7, se trataba de "leyes electorales" que impedían a los indígenas participar como candidatos electivos. Véase también el caso Comunidad Indígena Sawhoyamaxa, en el que la Corte señaló el deber de “....adoptar en su derecho interno las medidas legislativas, administrativas y de cualquier otro carácter que sean necesarias para crear un mecanismo judicial que haga efectivo el derecho de los pueblos indígenas de Paraguay al derecho de propiedad de su hábitat tradicional o tierras ancestrales..." (Corte IDH, Comunidad Indígena Sawhoyamaxa Vs. Paraguay, Sentencia de 29 de marzo de 2006, Serie C No. 146, párr. 201, punto i).

65 Señala Sagüés que “...cualquier regla jurídica doméstica (ley, decreto, reglamento, ordenanza, resolución, etc.) está sometida al control de convencionalidad. En Estados donde la doctrina jurisprudencial establecida por la Corte Suprema o el Tribunal Constitucional es obligatoria para los tribunales inferiores, ella también reviste materialmente condición de norma, y por ende, está captada por dicho control. Incluso, la constitución nacional no exceptuada en los veredictos aludidos. En este tramo tan importante de la doctrina que referimos, se parte tácitamente del supuesto de que el Pacto de San José se encuentra por encima de todo el ordenamiento jurídico del Estado, sin omitir a la propia Constitución. El Pacto asume así condición de supraconstitucionalidad. Por ello, como en el caso de 'La última Tentación de Cristo', cit., por ejemplo, la Corte Interamericana de Derechos Humanos reclamó a Chile modificar una cláusula de la Constitución local opuesta al Pacto, como efectivamente se hizo después..." (SAGüÉs, Néstor, El control de convencionalidad, ob. cit., punto 5).

66 En el caso de la Provincia de Buenos Aires, la Suprema Corte de Justicia, con ciertas variantes, se ha pronunciado por la procedencia del control oficioso de constitucionalidad (v. causas L. 69.523, "Barone”, sent. del 01-04-2003, L. 76.279, "Castillo", sent. del 1-10-2003; L. 80.156, "Martínez", sent. del 31-3-2004; L. 72.336, "Iommi”, sent. del 14-4-2004; L. 78.008, "Pereyra”, sent. del 14-04-2004) (Ílem causas L. 83.781 "Zaniratto”, sent. del 22-XII-2004; L. 74.311 "Benitez”, sent. del 29-XII-2004; L. 84.131 "Barreto", sent. del 8-VI-2005; L. 81.577 "Guzman", sent. del 8-VI-2005; L. 84.880 "CastiIlo”, sent. del 27-VI-2007; Ac. 88.847 "Peters”, sent. del 12-IX-2007, entre otras).

67 Caso Almonacid Arellano y otros, cit., supra nota 3, párr. 124. Véase Gialdino, Rolando, Control de constitucionalidad y de convencionalidad de oficio. Aportes del Derecho Internacional de los derechos humanos, en La Ley, 2008-C, p. 1295. Îdem Derecho Constitucional - Doctrinas Esenciales, Tomo I, p. 369.

68 Véase, Albar, Germán y Cançado Trinidades, Antonio, Reflexiones sobre el futuro del sistema interamericano de derechos humanos, en El futuro del sistema interamericano de protección de los derechos humano, ob. cit., p. 584. 
función no debe quedar limitada exclusivamente por las manifestaciones o actos de los accionantes en cada caso concreto, aunque tampoco implica que esa revisión deba ejercerse siempre, sin considerar otros presupuestos formales y materiales de admisibilidad y procedencia de ese tipo de acciones". ${ }^{9}$

Vista ahora la problemática no ya desde del derecho doméstico, sino del supranacional, lo cierto es que cuando las actuaciones llegan a la Corte regional, ella realiza -sin duda- esta verificación, aun de oficio, considerando que es la última intérprete de la normativa interamericana y que por una cuestión meramente procesal no puede permitir que el Estado infrinja, en este caso la Convención.

En ese orden de ideas téngase en cuenta que estamos hablando de un control normativo, no obstante, y como módulo para interpretar lo que venimos analizando, debe tenerse presente que el férreo principio de congruencia utilizado en el campo interno -por lo menos en los pleitos de marcadas esencia dispositiva-, ha sido morigerado por el tribunal aludido que aplicando el principio de iuria curia novit en verdad dilata en forma indirecta aquel postulado. ${ }^{70} \mathrm{Ha}$ dicho en este sentido ese cuerpo judicial que "...en el procedimiento ante un tribunal internacional una parte puede modificar su petición siempre que la contraparte tenga la oportunidad procesal de emitir su opinión al respecto...". ${ }^{71}$

\section{E. ¿Qué consecuencias derivan del control de convencionalidad hecho por la Corte IDH?}

Cuando dicho cuerpo jurisdiccional -luego de hacer el control de marras-, dispone que en el caso concreto se violó la convención, ${ }^{72}$ tal pronunciamiento es vinculante ${ }^{73}$ (arts. 62.3 y 68.1 del Pacto), y el Estado -tal cual vimos-, tiene la obligación de adaptar y en su caso modificar el derecho interno, incluyendo la propia Constitución como ocurrió en el caso de La Ultima Tentación de Cristo, ${ }^{74}$ bajo apercibimiento de incurrir en Responsabilidad Estatal.

69 Corte IDH, Caso Trabajadores Cesados del Congreso (Aguado Alfaro y otros) Vs. Perú, Sentencia de 24 de noviembre de 2006, párr. 128.

70 Hitters, Juan Carlos. 2006. Los Tribunales Supranacionales, La Ley, Buenos Aires, 2006-E, p. 818. En efecto, con buen tino ha dicho en el caso Fermín Ramírez, que tanto las víctimas como sus familiares o representantes pueden invocar derechos distintos de los comprometidos en la demanda de la Comisión. Corte IDH, Caso Fermín Ramírez Vs. Guatemala, Sentencia de 20 de junio de 2005, Serie C No. 126, párr. 116.

71 Corte IDH, Caso Aloeboetoe y otros Vs. Surinam, Reparaciones y Costas, Sentencia de 10 de septiembre de 1993, Serie C No. 15, párr 81; ídem Corte IDH, Caso Las Palmeras Vs. Colombia, Excepciones Preliminares, Sentencia de 4 de febrero de 2000, Serie C No. 67, párr. 31.

72 Corte IDH, Caso Yatama Vs. Nicaragua (cit.); Corte IDH, Caso La Cantuta Vs. Perú, Sentencia de 29 de noviembre de 2006, Serie C No. 162; Corte IDH, Caso Almonacid Arellano y otros Vs. Chile, Sentencia de 26 de septiembre de 2006, Serie C No. 154. Véase también Hitters, Juan Carlos, Los Tribunales Supranacionales, ob. cit.

73 De este tema ya nos hemos referido in extenso en el trabajo Hitters, Juan Carlos, ¿Son vinculantes los pronunciamientos...?, ob. cit.

74 Corte IDH, Caso "La Última Tentación de Cristo", cit. 
Esto quiere significar que desde esta vertiente la decisión interamericana no implica una abrogación automática del precepto local, pues es el país quien debe cumplir con el pronunciamiento regional.

Tal criterio también es aplicable, con ciertas particularidades, en los casos de las Opiniones Consultivas. ${ }^{75}$

Sin embargo en los delitos de lesa humanidad la cosa parece tener un matiz diferenciado ya que a nuestro criterio, en tales circunstancias, por ejemplo en los casos "Barrios Altos"; 76 "Tribunal Constitucional de Perú"77 y "La Cantuta"78 la Corte IDH se comportó como un verdadero Tribunal Constitucional declarando inaplicables en todo el país y con efecto erga omnes ${ }^{79}$ las leyes de amnistía dictadas en Perú. ${ }^{80}$

\section{CONCLUSIONES}

Hemos tratado de esbozar en forma sintética, lo que se ha dado en llamar en los últimos tiempos 'control de convencionalidad' mecanismo que debe ser llevado a

75 HitTers, Juan Carlos, ¿Son vinculantes los pronunciamientos...?, ob. cit., párr. 4.

76 Corte IDH, Caso Barrios Altos Vs. Perú, Sentencia de 14 de marzo de 2001, Serie C No. 75.

77 Corte IDH, Caso del Tribunal Constitucional Vs. Perú, Sentencia de 31 de enero de 2001, Serie C No. 71.

78 En efecto la Corte IDH en el Caso La Cantuta ha expresado que “...De las normas y jurisprudencia de derecho interno analizadas, se concluye que las decisiones de esta Corte tienen efectos inmediatos y vinculantes y que, por ende, la sentencia dictada en el caso Barrios Altos está plenamente incorporada a nivel normativo interno. Si esa Sentencia fue determinante en que lo allí dispuesto tiene efectos generales, esa declaración conforma ipso iure parte del derecho interno peruano, lo cual se refleja en las medidas y decisiones de los órganos estatales que han aplicado e interpretado esa Sentencia" (Caso La Cantuta Vs. Perú, cit., párr. 186).

79 El distinguido constitucionalista Néstor Pedro Sagüés en el trabajo que ya hemos citado (párr. 2), haciendo referencia a nuestra opinión cuando hablamos de la eventual anulación de las normas nacionales en los casos de Perú (Hitters, Juan Carlos, ¿Son vinculantes los pronunciamientos...?, ob. cit., nota 67), desde otra mirada sostiene que "...una cosa es que la Corte Interamericana repute jurídicamente inválidos esos preceptos y resuelva inaplicarlos por infligir el Pacto y otra es que esté habilitada para abolirlos...". Consideramos que desde el punto de vista estrictamente técnico la crítica es acertada porque en verdad no se produce una verdadera 'anulación' sino que la Corte le veda a Perú aplicar normas de impunidad en la totalidad de su territorio. Se ha dicho que los considerandos de tales pronunciamientos son vinculantes para todo el poder público peruano, incluso en aquellos en los que el Estado no haya sido parte. (Véase Tribunal Constitucional en el caso Arturo Castillo Chirinos, Expediente $\mathrm{N}^{\circ} 2730-06$ PA/TC, del 21 de julio de 2006, párrs. 12 y 13). Rescatamos la opinión del citado publicista ya que en verdad no ha habido ‘abolición' sino una declaración de inaplicabilidad de las leyes de impunidad, con efecto erga omnes, que produce un efecto similar.

$80 \mathrm{Si}$ bien en este artículo no nos ocupamos de la permeabilidad de las sentencias de la Corte IDH en el derecho interno, ni -por ende- de la recepción que tuvo la jurisprudencia interamericana por el más alto tribunal de ese país, cuestión ya abordada, como dijimos, en el trabajo ¿Son vinculantes los pronunciamientos...?, ob. cit.; repárese que por ejemplo en el caso "Simón" ("Simón, Julio H., y otros", sent. 14 de junio 2005, revista La Ley Buenos Aires, 29 de junio de 2005), entre otros la Corte Suprema de Justicia de la Nación Argentina, siguiendo la Corte Interamericana produjo la anulación de las leyes de obediencia de vida (ley 23.521) y punto final (ley 23.492). 
cabo, primero por los cuerpos judiciales domésticos, haciendo una 'comparación' entre el derecho local y el supranacional, a fin de velar por el efecto útil de los instrumentos internacionales, sea que surja de los tratados, del ius cogens o de la jurisprudencia de la Corte IDH; y luego esa tarea debe ser ejercida por el Tribunal regional si es que el caso llega a sus estrados.

Lo cierto es que los organismos judiciales internos antes que nada -y esto es obvio- deben cumplir una inspección de constitucionalidad, para evitar que en sus fallos se infrinja la carta suprema del país y en paralelo, ver si tales decisorios se acomodan con las convenciones internacionales ratificadas por la Argentina (arts. 1.1 y 2 CAHD).$^{81}$

No será ocioso repetir que el Tribunal Interamericano desde siempre viene haciendo esta revisión. Aunque la terminología aludida, esto es 'control de convencionalidad' ha sido utilizada en los últimos tiempos a partir de los asuntos que ya hemos citado.

Con respecto al contralor de marras la Corte del Pacto de San José hace referencia a las reglas legislativas, administrativas y de cualquier otro carácter, lo que implica, como vimos, que la inspección de 'compatibilidad' con la convención se efectúe sobre todo el material normativo del país. Ha establecido ese cuerpo que los pronunciamientos locales tienen que ser acatados y sólo en circunstancias excepcionales puede la Corte IDH ocuparse de examinar los respectivos procesos internos habida cuenta que élla no lleva a cabo una tercera o cuarta instancia. En ese aspecto ha sostenido que los jueces y tribunales domésticos están sujetos al imperio de la ley y obligados a aplicarla, pero cuando el Estado ha ratificado un tratado como el Pacto de San José 'sus jueces' como parte del aparato estatal, también están sometidos a él, lo que les obliga a velar para que sus efectos no sean mermados por la aplicación de normas jurídicas contrarios a su objeto y fin.

Esta verificación de convencionalidad tiene un carácter difuso ya que cada uno de los magistrados locales puede y debe cumplir la tarea, sin perjuicio de la postrera intervención de la Corte Interamericana.

Como consecuencia de lo expresado, va de suyo, que no sólo el Poder Judicial debe cumplir con las disposiciones del derecho supranacional, sino también el Ejecutivo y el Legislativo, tanto en el orden nacional, como provincial y municipal, bajo apercibimiento de generar responsabilidad internacional del Estado (arts. 1.1 y 2 de la CADH).

Cuando hacemos referencia a la 'revisión de oficio' queremos poner de relieve -obviamente- que en esas circunstancias la Corte está potenciada para hacerla aún cuando determinados planteos de convencionalidad no le sean articulados en forma expresa. Es decir que si una actuación arriba a sus estrados por la violación de deter-

81 Sobre este tema véase el excelente trabajo de Héctor Fix Zamudio y Eduardo Ferrer Mac-GreGor, Las sentencias de los Tribunales Constitucionales, Editorial UNAM - Porrúa, México, 2009, p. 79. 
minado derecho -por ejemplo el derecho a la vida-, ella puede ocuparse -digamosde la infracción al debido proceso legal.

Vale reiterar que tanto los judicantes nacionales como los de la Corte IDH deben buscar la 'compatibilidad' entre las normas locales -como reiteradamente lo hemos apuntado- y las reglas de los demás instrumentos internacionales a los que el país ha adherido, Tratados, Convenciones, Resoluciones, Declaraciones, Informes, etc., tales como el Protocolo de San Salvador; el Protocolo relativo a la Abolición de la Pena de Muerte; la Convención para Prevenir y Sancionar la Tortura; la Convención de Belém do Pará para la Erradicación de la Violencia contra la Mujer; la Convención sobre Desaparición Forzada; etcétera; que integran el corpus iuris convencional de los derechos humanos. Para esto también se debe tener en cuenta la 'jurisprudencia' de la Corte regional.

Por último parécenos necesario repetir que si ese cuerpo declara no convencional un determinado precepto doméstico -que haya sido aplicado o no- el país debe inmediatamente 'adaptar' la legislación interna -incluyendo su propia Constitución, como lo ha hecho Chile en el asunto ya citado- bajo apercibimiento de incurrir en responsabilidad estatal (arts. 1.1 y 2 de la CADH), y el ius cogens.

\section{BIBLIOGRAFÍA CITADA}

Cappelletti, Mauro, Acceso a la Justicia, Revista del Colegio de Abogados de La Plata, Año XXIII, $\mathrm{N}^{\circ} 41$.

CAppellettr, Mauro (1980). El "formidable problema" del control judicial y la contribución del análisis comparado, en Revista de Estudios Políticos, ISSN 0048-7694, $\mathrm{N}^{\circ}$ 13, Traducción de Faustino González.

Cappellettr, Mauro. (1978). Giustizia Costituzionale Soprannazionale, en Rivista Di Diritto Processual, anno XXXIII, T. II,

Cappellettr, Mauro (1987). La Justicia Constitucional (Estudios de Derecho Comparado), (México, UNAM).

Fix Zamudio, Héctor y Ferrer Mac-Gregor, Eduardo. (2009). Las sentencias de los Tribunales Constitucionales, (México, Editorial UNAM - Porrúa).

Germán, Albar y Cançado Trindade, Antonio (1998). Reflexiones sobre el futuro del sistema interamericano de derechos humanos, en El futuro del sistema interamericano de protección de los derechos humanos, (Costa Rica, Cox Editores).

GIALDINO, Rolando (2008). Control de constitucionalidad y de convencionalidad de oficio. Aportes del Derecho Internacional de los derechos humanos, en La Ley, 2008-C,

HitTers, Juan Carlos (2008). ¿Son vinculantes los pronunciamientos de la Comisión y de la Corte Interamericana de Derechos Humanos?, La Ley 2008-E.

Hitters, Juan Carlos (2003). Criterios establecidos por los órganos jurisdiccionales de los sistemas interamericano y europeos (Buenos Aires, La Ley), 2003-D.

HitTers, Juan Carlos (1991). Derecho Internacional de los Derechos Humanos, (Buenos Aires, Editorial Ediar). 
HitTers, Juan Carlos y Fappiano, Óscar (2007). Derecho Internacional de los Derechos Humanos, $2^{a}$ edición, Buenos Aires, Editorial Ediar.

HitTers, Juan Carlos, El Derecho Procesal Constitucional, en Revista El Derecho, T. 121. Hitrers, Juan Carlos (1987). Estudios de Derecho Constitucional Panameño, Compilador Jorge Fabrega, Panamá.

Hitters, Juan Carlos (1987). Legitimación democrática del Poder Judicial y Control de Constitucionalidad, en Justicia: Revista de Derecho Procesal, ISSN 0211-7754, № 2,

HitTers, Juan Carlos (2007), Los Tribunales Supranacionales, La Ley, Buenos Aires, 2006-E.

HitTers, Juan Carlos (2007), Responsabilidad del Estado por violación de Tratados Internacionales, La Ley, 2007-C.

Hitters, Juan Carlos (1997), Solución de controversias en el ámbito del Mercosur Hacia un derecho comunitario, La Ley, 1997-C.

Hitters, Juan Carlos. Técnica de los Recursos Extraordinarios, Librería Editora Platense, Buenos Aires, $2^{\text {a }}$ edición.

LoIANO, Adelina (2008). El marco conceptual del control de convencionalidad en algunos fallos de la Corte Suprema Argentina, "Arancibia Clavel", "Simón", "Mazzeo", en Albanese, Susana, Coordinadora, El control de convencionalidad, (Buenos Aires, Editorial Ediar).

Rey Cantor, Ernesto (2008). Control de Convencionalidad de las Leyes y Derechos Humanos, (México, Editorial Porrúa).

SAGüÉs, Néstor (2009), El control de convencionalidad. En particular sobre las Constituciones Nacionales, La Ley, 2009-B.

\section{Fallos y Casos Citados:}

- CNS, “García Méndez, Emilio y Musa, María Laura s/causa N 7537”. Voto del Dr. Enrique Santiago Petracchi.

- CSN, "Simón, Julio H., y otros", sent. 14 de junio 2005, revista La Ley, Buenos Aires, 29 de junio de 2005.

- Corte IDH, Caso "Instituto de Reeducación del Menor", Sentencia de 2 de septiembre de 2004, Serie C N ${ }^{\circ} 112$.

- Corte IDH, Caso "La Última Tentación de Cristo" [Olmedo Bustos y otros] Vs. Chile, Sentencia de 5 de febrero de 2001, Serie C No. 73.

- Corte IDH, Caso Acevedo Jaramillo y otros vs. Perú, Sentencia de 7 de febrero de 2006, Serie C No.144.

- Corte IDH, Caso Almonacid Arellano y otros Vs. Chile, Sentencia de 26 de septiembre de 2006, Serie C No. 154.

- Corte IDH, Caso Aloeboetoe y otros Vs. Surinam, Reparaciones y Costas, Sentencia de 10 de septiembre de 1993, Serie C No. 15.

- Corte IDH, Caso Barrios Altos Vs. Perú, Sentencia de 14 de marzo de 2001, Serie C No. 75.

- Corte IDH, Caso Boyce y otros Vs. Barbados, Sentencia de 20 de noviembre de 2007, Serie C No. 169.

- Corte IDH, Caso Carpio Nicolle y otros. Sentencia de 22 de noviembre de 2004. Serie C No. 117. 
- Corte IDH, Caso Castillo Petruzzi y otros Vs. Perú, Sentencia de 30 de mayo de 1999, Serie C No. 52.

- Corte IDH, Caso de la Masacre de Mapiripán vs. Colombia, Sentencia de 15 de septiembre de 2005, Serie C No. 13.

- Corte IDH, Caso del Penal Miguel Castro Castro Vs. Perú, Sentencia de 25 de noviembre de 2006, Serie C No. 160.

- Corte IDH, Caso del Tribunal Constitucional Vs. Perú, Sentencia de 31 de enero de 2001, Serie C No. 71.

- Corte IDH, Caso El Amparo Vs. Venezuela, Sentencia de 14 de septiembre de 1996, Serie C No. 28

- Corte IDH, Caso Fermín Ramírez Vs. Guatemala, Sentencia de 20 de junio de 2005, Serie C No. 126.

- Corte IDH, Caso Gutiérrez Soler. Sentencia de 12 de septiembre de 2005. Serie C No. 132.

- Corte IDH, Caso La Cantuta Vs. Perú, Sentencia de 29 de noviembre de 2006, Serie C No. 162.

- Corte IDH, Caso Las Palmeras Vs. Colombia, Excepciones Preliminares, Sentencia de 4 de febrero de 2000, Serie C No. 67.

- Corte IDH, Caso López Álvarez Vs. Honduras, Sentencia de 1 de febrero de 2006, Serie C No. 141.

- Corte IDH, Caso Myrna Mack Chang Vs. Guatemala, Sentencia de 25 de noviembre de 2003, Serie C No. 101.

- Corte IDH, Caso Palamara Iribarne vs. Chile, Sentencia de 22 de noviembre de 2005, Serie C No. 135.

- Corte IDH, Caso Raxcacó Reyes Vs. Guatemala, Sentencia de 15 de septiembre de 2005, Serie C No. 133.

- Corte IDH, Caso Suárez Rosero Vs. Ecuador, Sentencia de 12 de noviembre de 1997, Serie C No. 35.

- Corte IDH, Caso Tibi Vs. Ecuador, Sentencia de 7 de septiembre de 2004, Serie C No. 114.

- Corte IDH, Caso Trabajadores Cesados del Congreso (Aguado Alfaro y otros) Vs. Perú, Sentencia de 24 de noviembre de 2006, Serie C No. 158.

- Corte IDH, Caso Trabajadores Cesados del Congreso (Aguado Alfaro y otros). Vs. Perú, Solicitud de Interpretación de la Sentencia, Sentencia de 30 de noviembre de 2007, Serie C No. 174.

- Corte IDH, Caso Vargas Areco Vs. Paraguay, Sentencia de 26 de septiembre de 2006, Serie C No. 155.

- Corte IDH, Caso Yatama Vs. Nicaragua, Sentencia de 23 de junio de 2005, Serie C No. 127.

- Corte IDH, Comunidad Indígena Sawhoyamaxa Vs. Paraguay, Sentencia de 29 de marzo de 2006, Serie C No. 146.

- Corte IDH, Caso Genie Lacayo Vs. Nicaragua, Excepciones Preliminares, Serie C No. 21.

- Corte IDH, Caso Genie Lacayo. Solicitud de Revisión de la Sentencia de 29 de enero de 1997. Resolución de la Corte de 13 de septiembre de 1997. Serie C No. 45.

- Corte IDH. Caso Heliodoro Portugal Vs. Panamá. Excepciones Preliminares, Fondo, Reparaciones y Costas. Sentencia de 12 de agosto de 2008. Serie C No. 186. 
- Suprema Corte de Justicia Provincia de Buenos Aires causas L. 69.523, "Barone", sent. del 01-04-2003, L. 76.279, "Castillo", sent. del 1-10-2003; L. 80.156, "Martínez”, sent. del 31-3-2004; L. 72.336, “Iommi”, sent. del 14-4-2004; L. 78.008, "Pereyra”, sent. del 14-04-2004; causas L. 83.781 “Zaniratto”, sent. del 22-XII-2004; L. 74.311 "Benitez", sent. del 29-XII-2004; L. 84.131 "Barreto", sent. del 8-VI-2005; L. 81.577 "Guzman”, sent. del 8-VI-2005; L. 84.880 "Castillo", sent. del 27-VI-2007; Ac. 88.847 "Peters", sent. del 12-IX-2007.

- Tribunal Constitucional de Perú, Caso Arturo Castillo Chirinos, Expediente $\mathrm{N}^{\circ} 2730$ 06-PA/TC, del 21 de julio de 2006.

- Tribunal de Justicia de las Comunidades Europeas, Caso 6/64, “Costa vs. ENEL", en E.C.R., 1964. 